Christian Jaag*

\title{
Price Regulation and the Financing of Universal Services in Network Industries
}

\begin{abstract}
This article explores the complementary roles of price regulation and universal service regulation in network industries. It analyzes compensation for the universal service provider (USP) by public finances and a fund to which operators contribute. As long as the USP enjoys market power, price regulation may serve as a means to finance universal services. This implies allowing for price increases to compensate for the net cost of the universal service obligation. It releases competing operators or the general government budget from contributing to its financing but results in distorted pricing and reduced overall welfare due to inefficient entry. The analysis shows that current practices of costing and financing universal services may result in unintended market distortions. The article quantifies these effects and demonstrates how such distortions can be avoided.
\end{abstract}

Keywords: universal service obligation, price regulation, postal sector, telecommunications, network industries, net cost of the USO

*Corresponding author: Christian Jaag, Swiss Economics and University of St. Gallen, Switzerland, E-mail: christian.jaag@swiss-economics.ch

\section{Introduction}

The financing of universal service provision in network industries has traditionally relied on granting the provider a reserved area, for example, in the postal or telecommunications sectors. The need for alternative funding sources after full liberalization has increased the interest of regulators and the public in knowing the cost of universal services. Often, universal service providers (USPs) receive compensation for fulfilling a universal service obligation (USO). Adjusting consumer prices is an alternative to government funding. While there is quite a comprehensive literature on the costing of the USO and on price regulation in 
network industries, ${ }^{1}$ there has been little discussion so far on the effect of the regulatory environment (e.g. price regulation) on the burden of the USO and how it should be compensated in this context.

This article explores the two roles of price regulation in financing universal services: first, price control represents an important aspect of the regulatory framework, which needs to be taken into account when determining the burden of the USO. Second, it is a potential instrument to compensate the USP for this burden. The article thereby adds to the debate about appropriate rules for compensating and regulating universal services. ${ }^{2}$ Using a calibrated simulation model, the article compares different compensation mechanisms for the USP. It shows that the choice of the compensation mechanism and price regulation has an impact on the magnitude of the net cost of the USO and needs to be considered in the determination of the amount to be compensated. This implies that the policy debate on the financing of the USO must take into account other aspects of regulation, notably price control.

The remainder of this article is organized as follows. Section 2 discusses the current policy issues in financing universal services and the related literature. Section 3 briefly outlines a quantitative simulation model and its calibration. It takes the postal sector as a prominent and representative example where the financing of the USO is currently an important policy issue in light of recent full market opening and increasing competition from electronic communications means. ${ }^{3}$ Section 4 discusses the simulation results; Section 5 concludes with a summary of the main insights and concrete policy recommendations.

\section{Financing of universal service obligations}

Calculating the net cost of the USO is currently an important topic in many network industries. This is especially true for the European postal and

\footnotetext{
1 See, for example, Billette de Villemeur et al. (2003) for the postal sector and Tardiff and Taylor (2003) for telecommunications. For example, Laffont and Tirole (1990a, 1990b) discuss price regulation in multiproduct firms in general. CERP (2009) finds that there is no universal solution for postal price regulation. Postal regulators have to determine which price regulation mechanism (or combination of mechanisms) best suits their circumstances and objectives for their postal market.

2 The article does not weigh in on the current debate about the appropriate scope of the USO. See Jaag and Dietl (2011) for a discussion of how the USO might be adapted in the future.

3 See, for example, the recent report by Frontier Economics (2013) for the European Commission.
} 
telecommunications sectors, because these markets have recently been fully opened to competition. EU member countries need to implement financing mechanisms to compensate the USP without granting state aid, which is generally prohibited by Article 107 of the Treaty on the Functioning of the European Union. This requires understanding the effect of the USO financing mechanism on competition. The net cost of the USO according to profitability cost is the difference in the USP's profit with and without this obligation. ${ }^{4} \mathrm{~A}$ number of national regulatory authorities have commissioned reports on the net cost of the postal USO. ${ }^{5}$ To date, "the majority of NRAs have no established approach, and there is little precedent" (ERGP, 2011:6). As to telecommunications, the funding of networks and the inclusion/exclusion of broadband access in the USO pursuant to the state aid guidelines are currently important issues in the context of promoting broadband coverage. ${ }^{6}$

The costing of universal services has often been analyzed separately from its financing and irrespective of the regulatory environment. Only recently it has been argued that the market structure and the burden of the USO are directly related to other regulations and the funding mechanism in place. ${ }^{7}$ Jaag et al. (2011) provide an outline of how changes in the USP's cost structure affect pricing, market equilibria and hence indirectly the net cost. They also show that individual elements of the USO cannot be priced separately, as this would either result in inconsistent or biased net cost estimates. Boldron et al. (2009) argue that the effective cost/burden of USO is endogenous to regulation and funding mechanisms. Similar points are raised in Borsenberger et al. (2010) and in Jaag and Trinkner (2011) who discuss the appropriate tax base for a sharing mechanism and the competitive impact of various cost sharing and compensation mechanisms on the competitive equilibrium, respectively. Jaag (2011a) discusses the importance of a thorough definition of the counterfactual scenario

4 See Panzar (2000) and Cremer et al. (2000). Annex I of the Third Postal Directive defines the net cost calculation as follows: "The net cost of universal service obligations is any cost related to and necessary for the operation of the universal service provision. The net cost of universal service obligations is to be calculated, as the difference between the net cost for a designated universal service provider of operating with the universal service obligations and the same postal service provider operating without the universal service obligations."

5 See Copenhagen Economics (2008), Bergum (2009), Frontier Economics (2008) and Cohen et al. (2010) for recent applications of the profitability cost approach in the postal sector. Jaag et al. (2011) discuss these approaches. The European Committee for Postal Regulation (CERP) has published guidelines for calculating the net cost of the USO in the EU, see CERP (2008). The European Regulators Group for Postal Services (ERGP) has issued a draft Report on net cost calculation and evaluation of a reference scenario, see ERGP (2011).

6 See BEREC (2011) for a discussion of current policy issues in telecommunications in the EU. 7 See Armstrong (2008) for an analysis of access pricing in the context of a USO. 
- whether there is no USO at all or universal services are provided by an alternative operator - and its impact on the net cost of the USO.

Based on these considerations, it is apparent that merely calculating the net cost of a USO may not be adequate when devising fair compensation for a USP. ${ }^{8}$ Consequently, the Third Postal Directive 2008/6/EC in Article 7 states that':

Where a Member State determines that the universal service obligations [...] entail a net cost [...] and represent an unfair financial burden on the universal service provider (s), it may introduce:

- a mechanism to compensate the undertaking(s) concerned from public funds; or

- a mechanism for the sharing of the net cost of the universal service obligations between providers of services and/or users.

Hence, a compensation for the USP may only be introduced, if the USO entails a net cost and represents an unfair burden. In Article 12, the Third Postal Directive also states that:

Member States shall take steps to ensure that the tariffs for each of the services forming part of the universal service comply with the following principles:

- prices shall be affordable and must be such that all users, independent of geographical location, and, in the light of specific national conditions, have access to the services provided. [...],

- prices shall be cost-oriented and give incentives for an efficient universal service provision. Whenever necessary for reasons relating to the public interest, Member States may decide that a uniform tariff shall be applied, throughout their national territory and/or cross-border, to services provided at single piece tariff and to other postal items, [...]

Most of the countries in the EU define affordability in their national legislation (see Okholm et al., 2010). Basic letter and parcel post are the most important USO products where prices are regulated. All EU countries control prices of basic letter post. For that purpose, most of the countries use an ex-ante regulation, meaning that the USP must obtain the approval of the NRA before each price change. Only three countries (Denmark, Finland and Latvia) use ex-post approval.

Kleindorfer and Szirmay (2009) argue that liberalization pushes operators to become more customer oriented. However, they observe that pricing continues to be

8 See Jaag (2011b) for a discussion of various notions of an unfair burden.

9 The same rules for compensating the net cost also apply in the telecommunications sector; see Directive 97/33/EC on interconnection in telecommunications with regard to ensuring universal service and interoperability through application of the principles of Open Network Provision (ONP) and Directive 2002/22/EC (Universal Service Directive). 
rigorously regulated for universal services, and customer orientation in pricing at operators with universal service focus has been slow to develop. Ambrosini et al. (2011) describe the evolution of price regulation in the three postal directives: Article 12 of the First Postal Directive (97/67/EC) stated that prices must be affordable, geared to costs, transparent and non-discriminatory. It also proposed a uniform tariff throughout the national territory, whereas agreements with individual customers are possible. The Second Postal Directive (2002/39/EC) clarified the scope of price regulation, specifying that these prices

shall take into account avoided costs with the standard services covering the complete range of features offered for the clearance, transport, sorting and delivery of individual postal items. ${ }^{10}$

Such pricing linked to avoided costs bound two market segments (single-item and bulk), which had different demand characteristics (e.g. price elasticity) and therefore limited the ability for postal operators to compete on a level playing field (see Billette de Villemeur et al., 2008). The Third Postal Directive relaxed the avoided costs constraint on pricing; only the preamble now refers to this principle now. Nevertheless, postal operators' price setting in all EU countries is restricted at least for USO products and will likely remain so in the foreseeable future.

\section{A model of competition in the postal sector}

To illustrate the interaction of the costing of the USO with other regulation and show the potential of price control for indirect compensation, we use the example of the postal sector. The model employed for our analysis is based on Jaag and Trinkner (2011). See Valletti et al. (2002) for a similar analysis. We analyze the interaction of universal service financing and price regulation after full market opening, that is, after the abandonment of a reserved area in the market for mail. To isolate the relevant effects, we use a stylized model keeping things as simple and illustrative as possible. In particular, we do not model all dimensions of the USO.

We assume that there is one aggregate mail category. Two postal operators are active in the marketplace: A USP (incumbent) and a competitor (entrant). The two firms $i \in\{I, E\}$, each offers postal services which are imperfect substitutes. There is a continuum $[0,1] \subset \mathrm{R}_{+}$of different submarkets, where the size of the total market is of unit size. All submarkets share the same operatorspecific demand and marginal cost characteristics, but differ in fixed costs. We

10 Article 1 of Directive 2002/39/EC, amending article 12 of the 97/67/EC Directive. 
use a geographical interpretation of a submarket, such that submarket $r$ stands for a local delivery route. Hence, the total market can be divided into segments by region of delivery. If a firm decides to enter a certain submarket $r$, it has to pay the incremental cost associated with that submarket $f(r)$, where we assume that $f^{\prime}(r)>0 .{ }^{11}$ For the sake of simplicity, we make the following further assumptions:

Assumption 1: Submarkets are independent of each other. This implies that the competitive situation in one submarket does not affect the cost structure or demand in another market.

Assumption 2: The two operators $I$ (incumbent) and $E$ (entrant) possess similar technologies (cost structure) and compete in horizontally differentiated products.

Assumption 3: The sequence of decisions is as follows: First, a profit-maximizing incumbent chooses its optimum market coverage (geographical area coverage). Second, an entrant (competitor) sets its optimum coverage. Third, both operators set their price(s) for each of the submarkets. If there is a USO, the incumbent's market coverage is exogenously set to 1 (full coverage).

Assumption 4: Only letter mail is considered; the USO consists of a daily and nationwide mail delivery. ${ }^{12}$

Assumption 5: Marginal cost $c_{i}$ is constant.

In every submarket $r$ each operator makes a gross profit (or surplus) amounting to $s_{i}(r)$. Because all submarkets share the same demand characteristics and variable costs, the equilibrium prices in each submarket and therefore also $s$ depend only on the number of competitors. ${ }^{13}$ Typically, in the postal sector, $s_{i}(0)-f_{i}(0)>0$, while $s_{i}(1)-f_{i}(1)<0$. This implies that some submarkets (regions) are attractive to serve while others are not, and market entry will generally occur, albeit not with full coverage.

11 We refer to the incremental cost associated with serving a market as "incremental coverage cost" in the sense that it is the cost incurred when an operator extends its regional presence incrementally.

12 There is no general uniform pricing and affordability constraint in the model. In many countries, there are USO products which have to be delivered nationwide but are not subject to a uniformity or affordability constraint (e.g. bulk mail). We discuss scenarios with and without uniform pricing constraints to compare the respective competitive effects.

13 There is no reason for price differentiation within markets if the number of operators is same, because marginal costs do not vary across regions. 
From the perspective of operators, submarkets are ranked by increasing order of cost. Without USO, operators begin to cover the most densely populated areas and continue to cover less densely areas as long as it is profitable. Hence, each operator starts offering services from the submarket with the highest profit and leaves no gaps between served submarkets. If operator $i$ serves all submarkets $\left[0, r_{i}\right]$, its total profit will be

$$
\pi_{i}=\int_{0}^{r_{i}} s_{i}(r)-f_{i}(r) d r
$$

Given the sequence of decisions as in Assumption 3, the model is solved backward. First, the equilibrium in the price setting stage is determined in scenarios with and without price regulation. Then, the firms decide on their market coverage.

The operators' surpluses result from price competition in the continuum of submarkets. Price competition is driven by the users' demand for mail. Note that the incremental producer's surplus depends on the number of active firms, that is, whether the submarket is monopolistic or duopolistic. This is due to mutual business stealing (quantity effect) and competitive pressure on prices (price effect) in the duopolistic regions. We assume that there is one representative sender sending mail to destination region $r$ having quasilinear preferences with respect to money. It cares about mail conveyed by the two firms $I$ (incumbent) and $E$ (entrant). Total utility $u$ for mail sent to region $r$ is

$$
u^{r}\left(q^{r}, m\right)=m+\alpha_{I} q_{I}^{r}-\frac{\beta}{2 \gamma}\left(q_{I}^{r}\right)^{2}+\alpha_{E} q_{E}^{r}-\frac{\beta}{2 \gamma}\left(q_{E}^{r}\right)^{2}-\varepsilon \frac{\beta}{\gamma} q_{I}^{r} q_{E}^{r},
$$

where $q_{i}^{r}$ is the quantity of mail sent to region $r$ via operator $i$ and $m$ is the amount of money spent on other goods. The last term reflects the fact that the services offered by the two operators are not perfect substitutes but rather differentiated products. The higher the degree of differentiation, the closer parameter $\varepsilon$ is to zero. Parameter $\beta$ determines the market size and the slope of the demand curve. The difference between $\alpha_{I}$ and $\alpha_{E}$ is due to differences in delivery speed and reliability. Note that utility as described above primarily represents the representative sender's preferences toward mail. However, demand for mail is also determined by the receivers' preferences. This is taken care of by parameter $\gamma$. A receiver's likeliness to cause mail depends on whether mail is delivered to the doorstep or needs to be picked up in a P. O. box. ${ }^{14}$ Hence, the mode of delivery determines the value of $\gamma$ :

14 Transactional mail is often originated by recipients who choose to have a mail item delivered by the post instead of electronic alternatives. The importance of doorstep delivery for these customers is empirically demonstrated, for example, by Friedli et al. (2006). Due to the recipients' preferences, also senders of direct mail highly value doorstep delivery compared with P.O. box delivery. 


$$
\gamma=\left\{\begin{array}{cc}
1 & \text { withdoorstepdelivery, } \\
<1 & \text { withoutdoorstepdelivery }
\end{array}\right.
$$

All households which are not served with doorstep delivery by the incumbent are assumed to still receive mail in a P.O. box.

By computing the first-order conditions of the Lagrange function associated with the utility maximization problem and solving the resulting equation system, we obtain the linear demand functions for the two operators' products

$$
\begin{aligned}
& q_{I}^{r}\left(p_{I}^{r}, p_{E}^{r}\right)=\frac{\gamma}{\beta\left(1-\varepsilon^{2}\right)}\left(\alpha_{I}-\varepsilon \alpha_{E}-p_{I}^{r}+\varepsilon p_{E}^{r}\right), \\
& q_{E}^{r}\left(p_{E}^{r}, p_{I}^{r}\right)=\frac{\gamma}{\beta\left(1-\varepsilon^{2}\right)}\left(\alpha_{E}-\varepsilon \alpha_{I}-p_{E}^{r}+\varepsilon p_{I}^{r}\right) .
\end{aligned}
$$

The two operators' gross profit (producer surplus) functions in region $r$ write as

$$
\begin{gathered}
s_{I}^{r}=\left(p_{I}^{r}-c_{I}-\mu_{I}\right) q_{I}^{r}\left(p_{I}^{r}, p_{E}^{r}\right), \\
s_{E}^{r}=\left(p_{E}^{r}-c_{E}-\mu_{E}\right) q_{E}^{r}\left(p_{I}^{r}, p_{E}^{r}\right) .
\end{gathered}
$$

Parameters $\mu_{I}$ and $\mu_{E}$ are the contribution rates needed to finance the net cost of the USO, in case there is a compensation fund.

\subsection{Price setting without regulation}

If there is no price regulation, the two operators' producer surplus maximization with respect to prices results in the two reaction functions ${ }^{15}$ :

$$
\begin{gathered}
p_{I}^{r}= \begin{cases}\frac{1}{2}\left(\alpha_{I}+c_{I}+\mu_{I}\right) & \text { if } r>\tilde{r}, \\
\frac{1}{2}\left(\alpha_{I}-\varepsilon \alpha_{E}+c_{I}+\mu_{I}+\varepsilon p_{E}^{r}\right) & \text { if } r<\tilde{r},\end{cases} \\
p_{E}^{r}=\frac{1}{2}\left(\alpha_{E}-\varepsilon \alpha_{I}+c_{E}+\mu_{E}+\varepsilon p_{I}^{r}\right) .
\end{gathered}
$$

\footnotetext{
15 In the past, the postal USO generally called for uniform prices. With increased liberalization, this obligation has been relaxed in many countries. The Third Postal Directive even requires that any uniform tariff obligation be limited to single-piece items (mainly stamps and franked mail). Hence, the assumption of differentiated prices is plausible in the postal sector. Many postal operators effectively differentiate prices across geographical areas in their rebate system for large mailers.
} 
The differentiation of two cases results from the market being divided into a monopolistic region and a duopolistic region according to the market coverage decisions. Solving the reaction functions results in the following expressions for the incumbent's and the entrant's prices:

$$
\begin{gathered}
p_{I}^{r>\tilde{r}}=\frac{1}{2}\left(\alpha_{I}+c_{I}+\mu_{I}\right), \\
p_{I}^{r<\tilde{r}}=\frac{\alpha_{I}-\frac{\varepsilon \alpha_{I}}{2}-\varepsilon \alpha_{E}+\frac{\varepsilon \alpha_{E}}{2}+c_{I}+\mu_{I}+\varepsilon c_{E}+\varepsilon \mu_{E}}{2-\frac{\varepsilon^{2}}{2}}, \\
p_{E}=\frac{\alpha_{E}-\frac{\varepsilon \alpha_{E}}{2}-\varepsilon \alpha_{I}+\frac{\varepsilon \alpha_{I}}{2}+c_{E}+\mu_{E}+\varepsilon c_{I}+\varepsilon \mu_{I}}{2-\frac{\varepsilon^{2}}{2}} .
\end{gathered}
$$

These prices and the associated quantities determine each operator's surplus in all regions $r$.

\subsection{Price setting with regulation}

As discussed above, prices for postal products are often regulated. We, therefore, study scenarios with and without regulated prices. In the scenarios with price regulation, we first assume that prices are set uniformly over all markets such that the USP would just break even in the scenario without USO. Then, prices are frozen at that level also in the scenario with USO, and the USP is compensated by external funds or a compensation fund. An alternative means of financing the USO includes adjusting prices in the USO case such that the USP's profit remains unchanged compared to the situation without USO.

All regulated price levels cannot be determined algebraically. In the simulations below, they will be computed numerically.

\subsection{Optimum area coverage}

The incremental benefit of serving an additional market is given by the producer surplus which results from the price setting stage. The operators' incremental coverage cost $f_{i}(r)$ is the first derivate of the total fixed cost $F_{i}(r)$ associated with serving all regions up to $r$ : 


$$
F_{i}(r)=C_{i}+\delta_{i} r_{i}^{\theta} .
$$

The first part of total cost is fixed cost $C_{i}$, which is independent of quantities and the area covered by the operators. The second part reflects the time cost of delivery which increases convexly in the area covered according to the calibration of the parameters $\delta$ and $\theta$. Hence, the two operators' profits are

$$
\begin{gathered}
\pi_{I}=\left\{\begin{array}{c}
\pi_{I}(\bar{r})=\tilde{r} s_{I}^{r}+(\bar{r}-\tilde{r}) s_{I}^{r^{\prime}}-F_{I}(\bar{r}) \quad \text { if there is no USO, } \\
\pi_{I}(1)=\tilde{r} s_{I}^{r}+(1-\tilde{r}) s_{I}^{r^{\prime}}-F_{I}(1)+T \quad \text { if there is a USO }
\end{array}\right. \\
\pi_{E}=\tilde{r} s_{E}^{r}-F_{E}(\tilde{r}) .
\end{gathered}
$$

The last part of the incumbent's profit function with USO, $T$, reflects the transfer received as a compensation for providing universal services.

The optimum market coverage of the entrant and the incumbent are, respectively,

$$
\begin{gathered}
\tilde{r}=\operatorname{argmax}_{r_{E}} \int_{0}^{r_{E}} s_{E}(r)-f_{E}(r) d r, \\
\bar{r}=\operatorname{argmax}_{r_{1}} \int_{0}^{r_{I}} s_{I}(r)-f_{I}(r) d r .
\end{gathered}
$$

Due to the assumptions made, total cost is convex. This implies that only one type of asymmetric equilibrium can arise in which one operator is bigger than the other. Here, due to the sequence in Assumption 3, the entrant's coverage, $\tilde{r}$, is lower than the incumbent's, $\bar{r}^{16}$ This is due to the incremental surplus in the monopolistic segment being larger than in the duopolistic segment: there is a mutual business stealing (quantity effect) and competitive pressure on prices in the duopoly region (price effect) such that

$$
s_{i}^{r} \equiv s_{i}(r<\tilde{r})<s_{i}^{r^{\prime}} \equiv s_{i}(r \geq \tilde{r}) .
$$

Hence, in the absence of a USO, the specific cost structure together with the market penetration decisions results in a natural segmentation of the entire market into three regions (see Figure 1):

16 In our model, it is the sequence of decisions that results in the incumbent always serving at equilibrium a larger proportion of the market. This sequence reflects that the incumbent operator has traditionally been serving all markets due to the USO. 


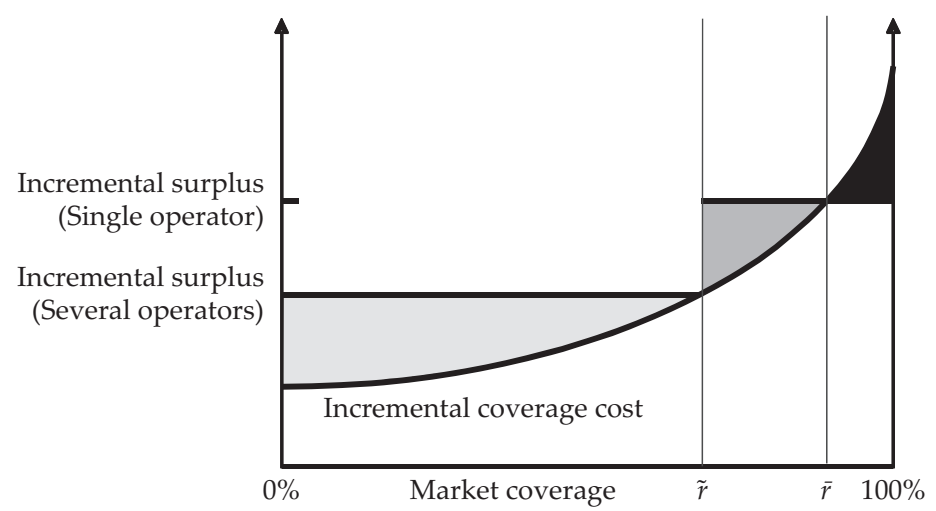

Figure 1: A network industry without USO

Source: Jaag and Trinkner (2011).

(1) In attractive markets (e.g. densely populated delivery areas), it is feasible for both companies to operate in parallel ("competitive region", $r<\tilde{r}$ ).

(2) In less attractive local delivery markets (e.g. semi-rural areas), an operator can make a profit only if there is no competitor. Hence, there will be a monopolistic operator in equilibrium ("monopolistic region", $\tilde{r}<r<\bar{r}$ ).

(3) In the least attractive local delivery markets (e.g. rural areas), incremental coverage costs are higher than incremental surplus, such that no operator serves this segment voluntarily ("unserved region", $r>\bar{r}$ ). It is assumed that all regions $r>\bar{r}$ are served with P.O. box delivery by the incumbent.

The introduction of a USO forces the USP to upgrade to home delivery in areas $r>\bar{r}$ in which the incremental coverage cost exceeds the incremental surplus from extending market coverage. This replaces the operator's coverage decision in the sequence of decisions and potentially necessitates some kind of compensation. The regulatory authority anticipates the resulting market equilibrium and introduces a compensation mechanism before the operators decision on their market coverage and pricing. Hence, from the operators' perspective, the contribution rates are predetermined. Also, the USP's compensation is determined ex ante and not dependent ex post on the funds actually collected. ${ }^{17}$

Given the incumbent's coverage, the optimum degree $\tilde{r}$ of the entrant's market penetration is

17 Since the model is deterministic and there are no information asymmetries, the contributions to the fund just match the predetermined compensation. 


$$
\tilde{r}=\left\{\begin{array}{cc}
0 & \text { if } s_{E}(0)<0 \\
1 & \text { if } s_{E}(1)>\delta_{E} \theta \\
{\left[\frac{s_{E}^{r}}{\theta \delta_{E}}\right]^{\frac{1}{\theta-1}}} & \text { otherwise }
\end{array}\right.
$$

where $s_{E}^{r}$ is the entrant's surplus in the duopolistic market segments. In analogy, without an USO, the incumbent penetrates the market to the degree

$$
\bar{r}=\left\{\begin{array}{cc}
0 & \text { if } s_{I}(0)<0 \\
1 & \text { if } s_{I}(1)>\delta_{I} \theta \\
{\left[\frac{s_{I}^{r^{\prime}}}{\theta \delta_{I}}\right]^{\frac{1}{\theta-1}}} & \text { otherwise }
\end{array}\right.
$$

where $s_{I}^{r^{\prime}}$ is the incumbent's surplus in the monopolistic market segments.

\subsection{Welfare}

Total welfare can be computed as the sum of the operators' profits (excluding government transfers) and consumer surplus ${ }^{18}$ :

$$
W=\pi_{I}+\pi_{E}-T^{e x t}+\int_{0}^{r} u^{r}-q_{I}^{r} p_{I}^{r}-q_{E}^{r} p_{E}^{r} d r .
$$

\subsection{Financing mechanisms}

Parameters $\mu_{I}$ and $\mu_{E}$ (contribution rates) in eqs [10-12] allow to introduce various financing mechanisms. Oxera (2007) provides an overview of financing instruments. Articles 7 and 9 of the Third Postal Directive guide the member states when implementing mechanisms to share the net cost of the USO. Especially, the provisions aim at preventing member states from raising new barriers to entry. The main funding mechanisms compliant with the Third Postal Directive are external financing and a compensation fund to which postal operators are obliged to contribute to. These contributions might be waived if an operator provides universal services ("pay-or-play"). If the burden of the USO can be absorbed by price adjustments, there may be no need for further compensation.

18 For simplicity, it is assumed that there is no shadow cost of public funds. 
In the EU, many member states have provisions for one or several financing mechanisms for the USO. The following countries may use external financing (direct state subsidies), if the USO turns out to be an unfair burden: Estonia, Latvia, Slovenia, Norway and Sweden. ${ }^{19}$ Eleven countries have provisions for a compensation fund, but so far no country has activated this fund: Austria, Belgium, Cyprus, France, Germany, Estonia, Italy, Netherlands, Portugal, Slovenia and Spain. Finland used to have a version of pay-or-play. ${ }^{20}$ Under this scheme, the "pay" element entails postal service providers without USO having to pay a fee to the tax office. The fee applies to new entrants with a restricted license to provide postal services in areas where the population density is above a certain threshold. If the operator decides to play, that is, to offer universal services, it will not be obliged to pay a fee and will be entitled to receive government funds.

In Switzerland, there is still a reserved area for letter mail up to $50 \mathrm{~g}$. Hence, Swiss Post enjoys some market power in this segment. It has to finance to cost of the USO entirely from its own receipts without any other compensation. Under the new postal legislation entered into force in fall 2012, there is a link to price regulation ensuring that regulated prices reflect the contribution of the respective revenue to the financing of the USO. The USO is, thus, financed by allowed price adjustments for the USP.

In the following, we consider four potential funding mechanisms to compensate the USP which reflect to mechanisms observed in practice:

\subsubsection{External financing}

With external financing, there is a direct subsidy from government funds. In this mechanism, there is no tax in the industry, and the net cost is reimbursed by the government directly:

$$
\begin{gathered}
\mu_{I}=\mu_{E}=0 \\
T^{\text {ext }} \text { such that } \pi_{I}(\bar{r})=\pi_{I}(1)
\end{gathered}
$$

where $T^{e x t}$ is a direct subsidy from government funds.

19 See Copenhagen Economics (2010) for an overview.

20 These license requirements are inconsistent with the Third Postal Directive as competing postal companies other than the universal service provider cannot be required to deliver mail 5 days per week. 


\subsubsection{Everyone contributes}

In case everyone contributes, there is a Universal Service Fund with no distinction between the USP and the entrant who both pay a contribution to the fund on a per-item basis ${ }^{21}$ :

$$
\mu_{I}=\mu_{E} .
$$

Consequently, there is no distinction between the USP and the entrant who both pay a contribution at rate $\mu$. If the net cost is determined before compensation ("sequential approach"), $\pi_{i}(1)$ is first calculated with $\mu_{I}=0 ; \mu_{E}=0$. The fund's budget restriction is satisfied if

$$
T=\mu \times\left[q_{I}^{r>\tilde{r}}(1-\tilde{r})+q_{I}^{r<\tilde{r}} \tilde{r}+q_{E} \tilde{r}\right] .
$$

The model is then solved numerically for $\mu=\mu_{I}=\mu_{E}$ such that $\pi_{I}(\bar{r})=\pi_{I}(1)$.

\subsubsection{Pay-or-play}

In a pay-or-play system, only the entrant (non-USP) contributes to the fund. The USP is waived from the tax in the sense that the incumbent provides universal services (and does not contribute to the fund) and the entrant contributes to the fund (but does not provide universal services). In our model specification and calibration, it is actually optimal for the entrant not to offer universal services himself but rather to contribute to the fund. ${ }^{22}$

$$
\mu_{I}=0 \text {. }
$$

Again, if the net cost is determined before compensation ("sequential approach"), $\pi_{I}(1)$ is first calculated using $\mu_{I}=0 ; \mu_{E}=0$. In this third model, the USP is waived from the output tax. The fund's budget restriction is satisfied if

$$
\mathrm{T}=\mu_{E} \times\left[q_{E} \tilde{r}\right] .
$$

The model is then solved numerically for $\mu_{E}$ such that $\pi_{I}(\bar{r})=\pi_{I}(1)$.

21 The Third Postal Directive does not impose a specific tax base for the compensation fund. The tax could also be based on profit, turnover or other variables (see, e.g. Gautier and Paolini, 2011, or Jaag and Trinkner, 2011).

22 In practice, the difficulty with a "pay-or-play" system is to define the balance between the provision of universal services and the reduction of the contribution to the fund. Here, we simplify by not differentiating between various degrees of universal service provision. Given the choice between providing full USO (together with the incumbent) and none, it is optimal for the entrant to "pay" and not to "play" in all scenarios discussed below. 


\subsubsection{Price adjustment}

With allowed price adjustments, the USP's “compensation” consists of the allowance to adjust its prices such that it breaks even both in the USO and in the non-USO scenarios:

$$
p_{I} \text { such that } \pi_{I}(\bar{r})=\pi_{I}(1)=0
$$

Hence, there is no net cost and, therefore, no need for further compensation. This financing mechanism makes only sense, if there is price regulation. It is assumed that the USP enjoys a certain degree of market power ${ }^{23}$ and that there is price control in terms of a uniform pricing and affordability constraint.

The different financing mechanisms for universal services yield the following direct and indirect effects on competition:

(1) A mechanism for compensating the incumbent providing universal services based on external funds has no effects on the market equilibrium. ${ }^{24}$

(2) With a financing of the USO by means of fund to which every operator contributes to, the incumbent's and the entrant's incremental surplus is reduced in all served submarkets. Intuitively, the compensation has a direct and an indirect effect on the USP's profit and hence on the net cost: The direct impact is that the USP contributes itself, such that the net compensation it receives is reduced. The indirect effect is that the competitor reduces its market coverage, which increases the USP's profit because his monopolistic market segment is extended.

(3) With a financing mechanism to which the incumbent does not contribute to, again the entrant serves a smaller region because of its contribution and its reduced incremental surplus. Due to the asymmetric taxation in the competitive region, the USP's incremental surplus increases in this region. Because the USP is exempt, all revenues in the submarkets $r>\tilde{r}_{\text {pop }}$ are unaffected. Hence, in contrast to the mechanism in which everyone contributes, the producer's surplus in these regions does not change. In all regions $r$ where $\tilde{r}_{p o p}<r<\tilde{r}_{\text {ext }}$, the USP is also exempt from contributing. In these regions, the USP is now the sole operator and earns a higher surplus in that submarket compared with the external funding scenario.

23 Hence, it is assumed that demand supports prices such that USP is able to break even.

24 Recall that the specification exhibits no cross-side effects between regions on the demand or cost side. 
(4) With price adjustments, the USP finances the USO itself by increasing its prices. This decreases its competitiveness and results in lost market share. It also invites the competitor to enter in additional submarkets.

\subsection{Model calibration}

The model is calibrated with data from Swiss Post in 2007 (see Jaag, 2007, and Jaag and Trinkner, 2011). In Switzerland, there was a reserved area up to $100 \mathrm{~g}$ at that time. Hence, the key parameters are calibrated for a partial monopoly version of the above model. There were mainly competitors in the market for unaddressed mail and newspapers. The data in Table 1 are the empirical basis for the calibration in Table 2. It includes addressed mail, unaddressed mail and newspapers.

Volume, revenue and average price data stem from Swiss Post's annual report. In terms of price elasticity of overall letter mail demand, Trinkner and

Table 1: Empirical basis for the model

\begin{tabular}{ll}
\hline Total volume & $5{ }^{\prime} 117$ million items \\
Total revenue & $3{ }^{\prime} 070$ million CHF \\
Average price & $0.60 \mathrm{CHF}$ \\
Total variable cost & $45 \%$ of total cost \\
Time cost of delivery & $30 \%$ of total fixed cost \\
Price elasticity of demand $\eta$ & -0.8 \\
\hline
\end{tabular}

Table 2: Key model parameters

\begin{tabular}{lll}
\hline$\beta=-1 / \eta \times p_{I} / q_{I}$ & $1.47 \times 10^{-10}$ & Market size parameter \\
$\alpha_{I}=\beta q_{I}+p_{I}$ & 1.35 & Preference for incumbent quality \\
$\alpha_{E}$ & 1.05 & Preference for entrant quality \\
$\delta_{I}$ & $3.75 \times 10^{6}$ & Incumbent's coverage-dependent delivery cost \\
$\delta_{E}$ & $2.00 \times 10^{6}$ & Entrant's coverage-dependent delivery cost \\
$c_{I}$ & 0.3 & Incumbent's marginal cost \\
$c_{E}$ & 0.25 & Entrant's marginal cost \\
$\gamma$ & 1 & Relative preference for doorstep delivery \\
$\gamma$ & 0.64 & Relative preference for P.O. box delivery \\
$\varepsilon$ & 0.70 & Degree of product differentiation \\
$\theta$ & 2.70 & Convexity of coverage cost function \\
\hline
\end{tabular}


Grossmann (2006) find in their empirical study for Switzerland a long-run price elasticity between -0.22 and -0.27 . From his survey of studies, Robinson (2007) finds that price elasticity measures for mail products typically range between -0.2 and -0.8 (see also Fève et al., 2006, for a recent study on mail price elasticities). In a similar exercise as ours, D’Alcantara and Amerlynck (2006) choose a value of -0.3 ; Dietl et al. (2005) use values between -0.3 and -0.5 for different mail products. Since we expect price elasticity to further increase over time, we choose a value for price elasticity of demand in the high range of these estimates.

From the values in Table 1 and additional data obtained from Swiss Post, the model parameters are calibrated as follows:

We assume an entrant with a slightly different business model than the incumbent's. Based on evidence from Sweden and Denmark (Bring Citymail), the Netherlands (Sandd), Switzerland (Quickmail) and other liberalized markets, we assume that the entrant chooses to deliver less frequently than the incumbent does and is able to pay the employees lower wages than the incumbent. Hence, we assume lower fixed and marginal costs. On the other hand, we calibrate demand such that more consumers choose the incumbent when both operators offer at the same price.

Without USO, the incumbent's optimum market coverage $\bar{r}$ is at $79 \%$, and the entrant's coverage is at $64 \%$. In the absence of price regulation, the USP's price in the monopolistic and competitive market segment is 0.825 and 0.591 , respectively. The entrant's price is 0.387 .

\section{Simulation results}

The model does not allow for closed-form results on the competitive effects of the difference financing mechanisms and the role of price regulation. Therefore, this section presents three numerical simulations based on the calibrated model and discusses the effect of the USO financing on prices, profits and welfare:

(1) In the first simulation, there is no price regulation. The effects of external, everyone pays and pay-or-play financing mechanisms on competition are calculated independently of the net cost calculations ("sequential approach").

(2) In the second simulation, there is no price regulation, but the competitive effect of the financing mechanisms is taken into account when determining the net cost ("integrated approach"). 
(3) In the third simulation, there is a uniform pricing and affordability constraint. The competitive effect of the financing mechanisms is taken into account when determining the net cost.

\subsection{Sequential approach without price regulation}

In the first scenario, there is no price regulation. The USP's compensation is determined independently of how it is financed. This implies that the competitive effects of financing the USO are not taken into account when calculating the net cost. The contribution rates are determined to cover the calculated difference in the USP's profits without USO and with USO but before compensation and its contribution.

Table 3 shows the simulation results. The actual (gross) compensation received by the USP is normalized for comparison across tables. It is the same with all financing mechanisms, because it is determined independently of them. With external financing, the net cost is compensated such that the USP's profit change due to the USO is equal to zero, see eq. [23]. In the everyone pays scenario, both operators' profits decrease, because they contribute to the financing of the USO based on the rule in eq. [25]. Compared to external financing, welfare decreases due to the distortions caused by the contribution rates. The

Table 3: Model results without price regulation: sequential calculation

\begin{tabular}{lccr}
\hline & & \multicolumn{2}{c}{ Financing mechanism } \\
\cline { 2 - 4 } & External & Everyone pays & Pay-or-play \\
\hline Compensation* & $1.92 \%$ & $1.92 \%$ & $1.92 \%$ \\
Per-unit contribution incumbent & 0.000 & 0.007 & 0.000 \\
Per-unit contribution entrant & 0.000 & 0.007 & 0.039 \\
Entrant market coverage & $64 \%$ & $63 \%$ & $55 \%$ \\
Incumbent consumer price $p_{I}^{r>\tilde{r}}$ & 0.825 & 0.829 & 0.825 \\
Incumbent consumer price $p_{I}^{r<\tilde{r}}$ & 0.591 & 0.597 & 0.599 \\
Entrant consumer price $p_{E}$ & 0.387 & 0.392 & 0.409 \\
USP profit change & $0.00 \%$ & $-0.59 \%$ & $5.67 \%$ \\
Entrant profit change & $0.00 \%$ & $-0.10 \%$ & $-0.93 \%$ \\
Welfare change** & $0.00 \%$ & $-0.69 \%$ & $-1.30 \%$ \\
\hline
\end{tabular}

Notes: * Relative to welfare with external financing, scenario without price regulation; ** relative to scenario with external financing, without price regulation and ${ }^{* *}$ compared to non-USO case; normalized by overall welfare in the non-USO case. 
same effects apply also - and even stronger - in the pay-or-play scenario where the compensation is calculated as in eq. [27]. There, USP profits from the USO and its compensation with a profit increase compared to the non-USO case by $5.67 \%$. This is due to the high per-unit contribution which reduces the entrant's competitiveness and market coverage (from 64\% without USO to 55\% with USO). Hence, the monopolistic region is extended compared to a situation without USO.

To summarize, without price regulation and with a pay-or-play mechanism, the market is distorted in the USP's favor, because market entry is obstructed due to a high burden on the competitor. The opposite is true in the case in which also the USP contributes to the financing of the USO.

\subsection{Integrated approach without price regulation}

Table 4 shows the results of the same simulations as in Table 3 with one difference: The contribution rate is now determined such that the USP profit after compensation and taxation is unchanged compared to a scenario without universal service ("integrated approach"). ${ }^{25}$ Hence, the net cost is computed in

Table 4: Model results without price regulation: integrated calculation

\begin{tabular}{lccr}
\hline & \multicolumn{2}{c}{ Financing mechanism } \\
\cline { 2 - 4 } & External & Everyone pays & Pay-or-play \\
\hline Compensation* & $1.92 \%$ & $2.79 \%$ & $0.55 \%$ \\
Per-unit contribution incumbent & 0.000 & 0.010 & 0.000 \\
Per-unit contribution entrant & 0.000 & 0.010 & 0.009 \\
Entrant market coverage & $64 \%$ & $63 \%$ & $62 \%$ \\
Incumbent consumer price $p_{I}^{r \tilde{r}}$ & 0.825 & 0.830 & 0.825 \\
Incumbent consumer price $p_{I}^{r<\tilde{r}}$ & 0.591 & 0.599 & 0.593 \\
Entrant consumer price $p_{E}$ & 0.387 & 0.395 & 0.392 \\
USP profit change & $0.00 \%$ & $0.00 \%$ & $0.00 \%$ \\
Entrant profit change & $0.00 \%$ & $-0.15 \%$ & $-0.24 \%$ \\
Welfare change** & $0.00 \%$ & $-1.01 \%$ & $-0.24 \%$ \\
\hline
\end{tabular}

Notes: * Relative to welfare with external financing, scenario without price regulation; ** relative to scenario with external financing, without price regulation and ${ }^{* \star *}$ compared to non-USO case; normalized by overall welfare in the non-USO case.

25 See Jaag and Trinkner (2011). 
market equilibrium simultaneously with the necessary contributions as in eqs [23], [25] and [27].

When a tax is introduced to finance the USO, not only the profit/deficit in the unserved region grows or shrinks, but there are also profit variations in the other regions which are taken into account in the integrated approach. Hence, changes in the USP's profit cannot occur by definition.

A comparison of Table 4 with Table 3 shows that the scenarios with external funding are the same: The competitive equilibrium is not affected by this kind of financing. The two scenarios with a fund differ, because the contributions to the fund are collected on a per-item basis while compensation is lump sum. Hence, the operators' pricing decisions are affected by the financing mechanism. If everyone pays, the contribution rate has two opposing effects. First, it compensates the USP for the net costs. Second, it raises the net cost as the tax is levied on the USP as well which creates an additional need for compensation. This necessitates higher tax rates for full compensation in equilibrium compared to the pay-or-play scenario. Moreover, the USP increases its prices due to the tax burden resulting from contributing to the funding of the USO. Direct compensation (first row) is lower in the pay-or-play case, because the entrant's optimum coverage is lower which represents a partial compensation for the USP since it extends its monopolistic region. This also results in a lower entrant profit and overall welfare.

The simulations show that it does not suffice to just calculate the deficit of the unprofitable products: As the financing affects also profitable products, these cannot be ignored in the costing of the USO. Compared to a sequential calculation of the USO net cost, an integrated calculation and compensation guarantees that there is no over- or undercompensation of the USP.

\subsection{Integrated approach with price regulation}

With price regulation in place, the USP's price is uniform and regulated such that it would break even without USO, see eq. [28]. ${ }^{26}$ The results differ quite strongly to those without price regulation (see Table 5). ${ }^{27}$ The first three columns show the situations with the same financing mechanisms and calculation method as in Table 4. The last column shows the result, if prices are such that

26 This setting is typical for the postal sector in many countries where prices are subject to direct approval (e.g. in Switzerland) or price cap regulation.

27 We assume that only the USP's prices are regulated, not the entrant's. 
Table 5: Model results with price regulation: integrated calculation

\begin{tabular}{lcccc}
\hline & \multicolumn{3}{c}{ Financing mechanism } \\
\cline { 2 - 5 } & External & Everyone pays & Pay-or-play & Price adj. \\
\hline Compensation* & $7.22 \%$ & $52.08 \%$ & $0.46 \%$ & $0.00 \%$ \\
Per-unit contribution incumbent & 0.000 & 0.166 & 0.000 & 0.000 \\
Per-unit contribution entrant & 0.000 & 0.166 & 0.166 & 0.000 \\
Entrant market coverage & $52 \%$ & $12 \%$ & $12 \%$ & $67 \%$ \\
Incumbent consumer price $p_{I}^{r>\tilde{r}}$ & 0.529 & 0.529 & 0.529 & 0.610 \\
Incumbent consumer price $p_{I}^{r<\tilde{r}}$ & 0.529 & 0.529 & 0.529 & 0.610 \\
Entrant consumer price $p_{E}$ & 0.365 & 0.448 & 0.448 & 0.394 \\
USP profit change & $0.00 \%$ & $0.00 \%$ & $0.00 \%$ & $0.00 \%$ \\
Entrant profit change & $-1.00 \%$ & $-2.35 \%$ & $-2.35 \%$ & $0.79 \%$ \\
Welfare change & $22.37 \%$ & $25.49 \%$ & $25.49 \%$ & $13.09 \%$ \\
\hline
\end{tabular}

Notes: * Relative to welfare with external financing, scenario without price regulation; ** Relative to scenario with external financing, without price regulation; and ${ }^{* \star}$ Compared to non-USO case; normalized by overall welfare in the non-USO case.

the USP just breaks even with USO. ${ }^{28}$ It would not make sense to combine a break-even constraint with another financing mechanism, because the net cost is equal to zero by definition. With all four financing mechanisms, price control results in a price decrease in both the monopolistic and the competitive region due to the incumbent's strong market power. There are strong welfare gains compared to the scenarios without price regulation.

Compared to the results in the three first columns in Table 4 without price regulation, compensation is higher with price regulation, because no price adjustment is allowed. This price freeze also results in the two scenarios with a fund being equivalent. The only difference is the USP receiving a high compensation in the case that everyone pays to offset its own contribution (first row). The USP's low prices and the high contribution rates in all scenarios keep the entrant mostly out of the market.

If the USP is allowed to adjust prices to break even (fourth column), prices increase because no other means of financing the USO are available. This increases the entrant's profit compared to the other scenarios due to the increase in its net-of-tax prices. Moreover, the USP's opportunity to compensate the net cost of the USO by increasing its price releases the competitor from contributing

28 The model calibration allows the market that actually supports such an equilibrium. 
to its financing. However, compared to other financing mechanisms (with price regulation), it degrades welfare, because it invites inefficient entry.

\subsection{Sensitivity analysis}

The market equilibrium in all scenarios is driven by the entrant's market coverage decision which itself depends on the incumbent's pricing. A sensitivity analysis analyzes these effects in more detail. It bases on the last set of simulations which assume that prices are regulated to be uniform such that the incumbent breaks even. Table 6 reports the values for the incumbent's regulated price in equilibrium depending on the price elasticity of demand $(\eta)$ and the degree of (exogenous) product differentiation $(\varepsilon)$. Recall that the higher the degree of differentiation, the closer parameter $\varepsilon$ is to zero. Table 7 shows the competitor's coverage with the same set of parameter values for the price elasticity of demand and the degree of product differentiation.

With low price elasticities of demand, a high degree of product differentiation implies a high USP price to break even (Table 6). This is due to the competitor's increased market coverage (Table 7). With high price elasticities, this effect is reversed. While the competitor's market coverage still increases in the degree of product differentiation, its pricing is now more aggressive (and applies in more regions), hence forcing also the incumbent to set its prices low.

Table 6: Incumbent's consumer price depending on product differentiation and price elasticity of demand

\begin{tabular}{rrrrr}
\hline & $\boldsymbol{\eta}=\mathbf{0 . 7 4}$ & $\boldsymbol{\eta}=\mathbf{0 . 7 6}$ & $\boldsymbol{\eta}=\mathbf{0 . 7 8}$ & $\boldsymbol{\eta}=\mathbf{0 . 8 0}$ \\
\hline$\varepsilon=0.64$ & 0.800 & 0.766 & 0.729 & 0.608 \\
$\varepsilon=0.66$ & 0.791 & 0.757 & 0.720 & 0.608 \\
$\varepsilon=0.68$ & 0.783 & 0.749 & 0.711 & 0.609 \\
$\varepsilon=0.70$ & 0.775 & 0.740 & 0.703 & 0.610 \\
\hline
\end{tabular}

Table 7: Competitor's coverage depending on product differentiation and price elasticity of demand

\begin{tabular}{rrrrr}
\hline & $\boldsymbol{\eta}=\mathbf{0 . 7 4}$ & $\boldsymbol{\eta}=\mathbf{0 . 7 6}$ & $\boldsymbol{\eta}=\mathbf{0 . 7 8}$ & $\boldsymbol{\eta}=\mathbf{0 . 8 0}$ \\
\hline$\varepsilon=0.64$ & $91 \%$ & $90 \%$ & $89 \%$ & $73 \%$ \\
$\varepsilon=0.66$ & $89 \%$ & $88 \%$ & $86 \%$ & $71 \%$ \\
$\varepsilon=0.68$ & $86 \%$ & $85 \%$ & $83 \%$ & $69 \%$ \\
$\varepsilon=0.70$ & $84 \%$ & $83 \%$ & $80 \%$ & $67 \%$ \\
\hline
\end{tabular}


The more elastic demand, the lower is the USP's equilibrium price. This reduces the competitor's profitability and results in its lower market coverage.

\section{Conclusions}

Universal services in network industries impose a net cost on designated operators. There is currently some diversity in practice to compensate operators offering universal services. An important policy challenge is to design the compensation for the USO such that it is competitively neutral.

This article shows that the net cost of USO - defined as the difference in the USP's profit with and without USO - very much depends on the design of the compensation mechanism. If the USP is compensated from the general government budget, this does not affect the market equilibrium. In this case, USO costing and financing are independent of each other. However, if there is a tax levied from the operators in the market in order to finance the USO, this distorts the market equilibrium and has to be taken into account when determining the net cost.

Given the complex interaction between the costing and financing of the USO and the USP's price regulation, an integrated approach to USO costing and financing should, therefore, be applied. This implies that the regulatory authority set the contribution rate or its price control in a way that the USP's profits remain unchanged comparing a situation without USO and one with USO after compensation. If this is not done, the USP may be significantly over- or undercompensated. Simulations show that a compensation fund to which all operators (including the USP) contribute according to their market shares results in an undercompensation of the USP. In contrast, if the USP is excluded from contributions, this will unambiguously result in over-compensation and contribution rates act as an effective barrier to entry for potential competitors.

If the USP enjoys a certain market power, its prices are likely to be regulated within or in addition to the USO, which results in restricted profit opportunities. Compensation for universal service provision works in the opposite direction by replicating the USP's hypothetical profit without USO. Both regulatory interventions affect each other's rationale and effect. Allowing the USP to adjust its prices to compensate for the burden of the USO and as a substitute for direct compensation is a straightforward approach to financing the USO and a viable alternative to funds from government or a compensation fund. It also reduces regulatory complexity and is pro-competitive, since it strengthens the competitor by releasing it from contributing to financing the USO and allowing it to increase its market coverage profitably due to USP's increased prices. However, it degrades overall welfare due to inefficient entry. 


\section{References}

Ambrosini, X., S. Breville, J. Cornée, and O. Klargaard. 2011. "Pricing Strategies in Regulated Markets - Innovative Pricing in the Postal Sector," 12 Competition and Regulation in Network Industries 57-83.

Armstrong, M. 2008. "Access Pricing, Bypass and Universal Service in Post," 7 Review of Network Economics 172-187.

BEREC. 2011. "Work Programme 2012 BEREC Board of Regulators."

Bergum, Kristin. 2009. "Calculating the Net Cost of the USO: A Practical Example from Norway," in Michael A. Crew, Paul R. Kleindorfer, and James I. Campbell, eds. Handbook of Worldwide Postal Reform. Cheltenham: Edward Elgar.

Billette de Villemeur, E., H. Cremer, B. Roy, and J. Toledano. 2003. "Optimal Pricing and Price-Cap Regulation in the Postal Sector," 24 Journal of Regulatory Economics 49-62.

Bilette de Villemeur, E., H. Cremer, F. Boldron, and B. Roy. 2008. "Worksharing: A Calibrated Model," 7 Review of Networks Economics 272-293.

Boldron, F., C. Borsenberger, D. Joram, S. Lecou, and B. Roy. 2009. "A Dynamic and Endogenous Approach for Financing USO in a Liberalized Environment," in Michael A. Crew and Paul R. Kleindorfer, eds. Progress in the Competitive Agenda in the Postal and Delivery Sector. Cheltenham: Edward Elgar.

Borsenberger, Claire, Helmuth Cremer, Philippe De Donder, Denis Joram, and Bernard Roy. 2010. "Funding the Cost of Universal Service in a Liberalized Postal Sector," in Michael A. Crew and Paul R. Kleindorfer, eds. Heightening Competition in the Postal and Delivery Sector. Cheltenham: Edward Elgar.

CERP. 2008. "Guidelines for Calculating the Net Cost of the Universal Service Obligations."

CERP. 2009. "Recommendation on Best Practices for Price Regulation."

Cohen, Robert, Charles McBride, and John C. Panzar. 2010. "The Cost of the USO in the United States," in Michael A. Crew and Paul R. Kleindorfer, eds. Heightening Competition in the Postal and Delivery Sector. Cheltenham: Edward Elgar.

Copenhagen Economics. 2008. “What Is the Cost of Post Danmark's Universal Service Obligation?" Study on Behalf of the Danish Chamber of Commerce.

Copenhagen Economics. 2010. "Main Developments in the EU Postal Sector (2008-2010)," Study Commissioned by the European Commission (GD Internal Market).

Cremer, H., A. Grimaud, and J.-J. Laffont. 2000. "The Cost of Universal Service in the Postal Sector," in Michael A. Crew and Paul R. Kleindorfer, eds. Current Directions in Postal Reform. Boston, MA: Kluwer Academic Publishers.

D’Alcantara, G., and B. Amerlynck. 2006. "Profitability of the Universal Service Postal Operator under Entry with Economies of Scale in Collection and Delivery," in Michael A. Crew and Paul R. Kleindorfer, eds. Progress Toward Liberalization of the Postal and Delivery Sector. New York, NY: Springer.

Dietl, H., U. Trinkner and R. Bleisch. 2005. "Liberalization and Regulation of the Swiss Letter Market," in Michael A. Crew and Paul R. Kleindorfer, eds. Regulatory and Economic Challenges in the Postal and Delivery Sector. New York: Kluwer.

ERGP. 2011. "Draft Report on Net Cost Calculation and Evaluation of a Reference Scenario." 
Fève, F., J.-P. Florens, and S. Richard. 2006. "Microeconomic Demand Modelling for Price Elasticities," in Michael A. Crew and Paul R. Kleindorfer, eds. Liberalization of the Postal and Delivery Sector. Cheltenham: Edward Elgar.

Friedli, B., C. Jaag, D. Krähenbühl, O. Nielsen, S. Pihl, and U. Trinkner. 2006. “Consumer Preferences and Last Mile Pricing in the Postal Sector," in Michael A. Crew and Paul R. Kleindorfer, eds. Liberalization of the Postal and Delivery Sector. Cheltenham: Edward Elgar.

Frontier Economics. 2008. "Net Costs of Elements of the Universal Service," Report Prepared for Postcomm.

Frontier Economics. 2013. "Study on the Principles Used to Calculate the Net Costs of the Postal USO," Report Prepared for the European Commission.

Gautier, A., and D. Paolini. 2011. "Universal Service Financing in Competitive Postal Markets: One Size Does Not Fit All," 10 Review of Network Economics 1-30.

Jaag, C. 2007. "Liberalization of the Swiss Letter Market and the Viability of Universal Service Obligations," 143 Swiss Journal of Economics and Statistics 261-282.

Jaag, C., U. Trinkner, J. Lisle, N. Waghe, and E. Van Der Merwe. 2011. "Practical Approaches to USO Costing and Financing," 12 Competition and Regulation in Network Industries, Intersentia 108-108.

Jaag, C. 2011a. "Entry Deterrence and the Calculation of the Net Cost of Universal Service Obligations," 10 Review of Network Economics 1-19.

Jaag, C. 2011b. "What Is an Unfair Burden? Compensating the Net Cost of Universal Service Provision," 10 Review of Network Economics 1-32.

Jaag, C, and H. Dietl. 2011. "Postal and Regulatory Reform in Intermodal Competition," in Kristian Sund and Derek Osborn, eds. The Future is in the Post, Vol. 2: Perspectives on Transformation in the Postal Industry. Faringdon: Libri Publishing.

Jaag, C., and U. Trinkner. 2011. "The Interaction between Universal Service Costing and Financing in the Postal Sector: A Calibrated Approach," 39 Journal of Regulatory Economics 89-110.

Jaag, C., M. Koller, and U. Trinkner. 2009. "Calculating the Cost of the USO - The Need for a Global Approach," in Michael A. Crew and Paul R. Kleindorfer, eds. Progress in the Competitive Agenda in the Postal and Delivery Sector. Cheltenham: Edward Elgar.

Kleindorfer, P.R., and Z. Szirmay. 2009. "Pricing Practice in the Postal Industry: Current Approaches and Challenges Under Liberalization," Research paper, INSEAD \& Roland Berger.

Laffont, J.-J., and J. Tirole. 1990a. "The Regulation of Multiproduct Firms: Part I: Theory," 43 Journal of Public Economics 1-36.

Laffont, J.-J., and J. Tirole. 1990b. "The Regulation of Multiproduct Firms: Part II: Applications to Competitive Environments and Policy Analysis," 43 Journal of Public Economics 37-66.

Okholm, H.B., M. Winiarczyk, A. Moller, and C. Kastberg Nielsen. 2010. "Main Developments in the Postal Sector (2008-2010)," Report Commissioned by DG Internal Market.

Oxera. 2007. "Funding Universal Service Obligations in the Postal Sector," Report Prepared for La Poste, De Post-La Poste, Hellenic Post, Poste Italiane, P\&T Luxembourg, Correos, Magyar Posta, Cyprus Post, Poczta Polska.

Panzar, J. 2000. "A Methodology for Measuring the Costs of Universal Service Obligations," 12 Information Economics and Policy 211-220.

Robinson, A. 2007. "A Review of Price Elasticity Models for Postal Products," Pitney Bowes Background Paper 2007-01.

Tardiff, T.J., and W.E. Taylor. 2003. "Aligning Price Regulation with Telecommunications Competition," 2 Review of Network Economics 388-354. 
Trinkner, U., and M. Grossmann. 2006. "Forecasting Swiss Mail Demand," in Michael A. Crew and Paul R. Kleindorfer, eds. Progress Toward Liberalization of the Postal and Delivery Sector. New York, NY: Springer.

Valletti, T., S. Hoernig, and P. Barros. 2002. "Universal Service and Entry: The Role of Uniform Pricing and Coverage Constraints," 21 Journal of Regulatory Economics 169-190. 